\section{Commentary: The importance and treachery of patient selection for neonatal heart transplant}

\author{
David P. Bichell, MD
}

Lin and colleagues ${ }^{1}$ report an impressive 3-decade singlecenter experience with neonatal heart transplantation that also illustrates chapters in the story of neonatal heart surgery. In the first decade of the series, palliative surgery for hypoplastic left heart syndrome (HLHS) and its variants carried a prohibitive risk, so transplantation was a principal treatment strategy for HLHS. With subsequent improving Norwood outcomes, and in consideration of $25 \%$ transplantation waitlist mortality, the second and present decades show a decline in the number of primary neonatal transplantations performed. Few centers now perform enough primary neonatal transplantations to discuss comparative approaches. Meanwhile, despite improved outcomes for standard-risk patients undergoing the Norwood palliation, high-risk HLHS patients have enjoyed little if any improvement in long-term outcome, and primary transplantation may play a larger role in the next chapter. ${ }^{2}$

Lin and colleagues suggest that in light of excellent transplantation outcomes in the neonates and emerging improvements in mechanical support options, a refined ability to identify and bridge patients with high-risk anatomy may lead to a reexpansion of the role for primary transplantation in this group. However, it remains to be shown whether high-risk candidates carry their risk to transplantation even if it delivered better support to survive the waitlist. Identifying patients at high risk for poor long-term outcome is important to improved results of any intervention, but refined risk stratification does not ensure that there is an acceptable intervention for all strata of risk.

\footnotetext{
From the Department of Cardiac Surgery, Monroe Carell Jr Children's Hospital, Vanderbilt University Medical Center, Nashville, Tenn.

Disclosures: The author reported no conflicts of interest.

The Journal policy requires editors and reviewers to disclose conflicts of interest and to decline handling or reviewing manuscripts for which they may have a conflict of interest. The editors and reviewers of this article have no conflicts of interest

Received for publication Feb 1, 2021; revisions received Feb 1, 2021; accepted for publication Feb 1, 2021; available ahead of print Feb 5, 2021

Address for reprints: David P. Bichell, MD, Monroe Carell Jr Children's Hospital, Vanderbilt University Medical Center, 5247 Doctors' Office Tower, 2200 Children's Way, Nashville, TN 37232-9292 (E-mail: david.bichell@vumc.org).

J Thorac Cardiovasc Surg 2021;162:1370-1

$0022-5223 / \$ 36.00$

Copyright (c) 2021 by The American Association for Thoracic Surgery

http://dx.doi.org/10.1016/j.jtcvs.2021.02.005
}

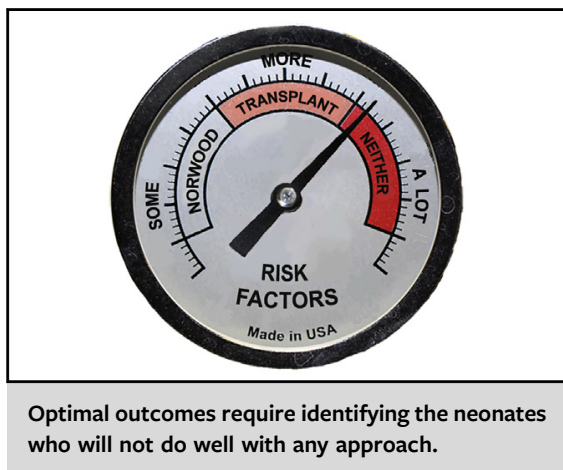

CENTRAL MESSAGE

Despite excellent transplantation

outcomes, an improved mechani-

cal bridge, and donor pool expan-

sion, identifying which neonates

will not do well with any approach

remains a most important priority.

Evidence supports that some high-risk features might not be successfully served by any strategy including transplantation. In utero left atrial hypertension from atrial restriction promotes pulmonary arteriolar and venous thickening, lymphatic dilation, and high pulmonary resistance that may thwart the success of the Glenn procedure, Fontan procedure, or transplantation for neonates with restrictive interatrial connection. ${ }^{3,4}$ There is evidence showing that for low birth weight infants, a strategy of delaying surgery until weight gain might not mitigate the elevated risk of mortality for these infants at cardiac surgery. ${ }^{5}$ Some unmodifiable baggage may similarly be carried across the bridge to transplantation.

Current data, including the series reported by Lin and colleagues, show that after accounting for waitlist attrition and post-transplantation mortality, 5-year survival is $<60 \%$ for a strategy of primary transplantation for HLHS, and survival is similar for post-Norwood transplantation. ${ }^{1,6,7}$ If high-risk patients carry their risk despite improved support, they may face coin-toss odds for long-term survival whether palliated, primarily transplanted, or palliated then transplanted.

Excellent results following neonatal transplantation, combined with mechanical improvements in bridge to transplantation, certainly enliven the discussion of expanding transplantation for high-risk neonates. It may not be true that identifying high-risk patients for support to primary transplantation rather than Norwood will improve outcomes for those identified as high risk. It may instead be truer that identifying high-risk patients whose outcomes dominate the mortality rosters of all known approaches need an as-yet unknown new 
pathway. Identifying neonates who will not do well with any approach may be the most important part of the next chapter.

\section{References}

1. Lin Y, Davis TJ, Zorilla-Vaca A, Wojcik BM, Miyamoto SD, Everitt MD, et al. Neonatal heart transplant outcomes: a single institution experience. J Thorac Cardiovasc Surg. 2021;162:1361-8

2. Tanem J, Rudd N, Rauscher J, Scott A, Frommelt MA, Hill GD. Survival after Norwood procedure in high-risk patients. Ann Thorac Surg. 2020;109:828-33.

3. Graziano JN, Heidelberger KP, Ensing GJ, Gomez CA, Ludomirsky A. The influence of a restrictive atrial septal defect on pulmonary vascular morphology in patients with hypoplastic left heart syndrome. Pediatr Cardiol. 2002;23:146-51.
4. Lowenthal A, Kipps AK, Brook MB, Meadows J, Azakie A, Moon-Grady AJ. Prenatal diagnosis of atrial restriction in hypoplastic left heart syndrome is associated with decreased 2-year survival. Prenat Diagn. 2012;32:485-90.

5. Hickey EJ, Nosikova Y, Zhang H, Caldarone CA, Benson L, Redington A, et al. Very low-birth-weight infants with congenital cardiac lesions: is there merit in delaying intervention to permit growth and maturation? J Thorac Cardiovasc Surg. 2012;143:126-36.e1.

6. Chrisant MRK, Naftel DC, Drummond-Webb J, Chinnock R, Canter CE Boucek MM, et al. Fate of infants with hypoplastic left heart syndrome listed for cardiac transplantation: a multicenter study. J Heart Lung Transplant. 2005; 24:576-82.

7. Alsoufi B, Deshpande S, McCracken C, Kogon B, Vincent R, Mahle W, et al. Outcomes and risk factors for heart transplantation in children with congenital heart disease. J Thorac Cardiovasc Surg. 2015;150:1455-62.e3.
See Article page 1361.

\section{Commentary: Neonatal heart transplant: A good option in a bad situation}

\author{
Douglas M. Overbey, MD, MPH, ${ }^{\mathrm{a}, \mathrm{b}}$ and \\ Andrew J. Lodge, $\mathrm{MD}^{\mathrm{b}}$
}

Lin and colleagues ${ }^{1}$ present an excellent analysis of 30 years of outcomes data for neonatal orthotopic heart transplantation with a single institution retrospective study. This study is among the few long-term outcome series for neonatal transplant and is a valuable addition to the literature. The outcomes are generally favorable, suggesting neonatal transplantation as a reasonable approach to congenital cardiac malformations where the risk of palliative surgery is high. ${ }^{1}$ This study focuses on neonatal cardiac transplants, due to the excellent outcomes described in this cohort, believed to be due to immunologic privilege. ${ }^{2}$

Children's Hospital Colorado was an early advocate of neonatal heart transplantation, and accrued a series of 21

\footnotetext{
From the ${ }^{\mathrm{a} C a r d i o t h}$ oracic Surgery Residency Program and ${ }^{\mathrm{b}}$ Division of Cardiovascular and Thoracic Surgery, Department of Surgery, Duke University Medical Center, Durham, NC.

Disclosures: The authors reported no conflicts of interest.

The Journal policy requires editors and reviewers to disclose conflicts of interest and to decline handling or reviewing manuscripts for which they may have a conflict of interest. The editors and reviewers of this article have no conflicts of interest.

Received for publication Feb 2, 2021; revisions received Feb 2, 2021; accepted for publication Feb 3, 2021; available ahead of print Feb 12, 2021.

Address for reprints: Andrew J. Lodge, MD, Division of Cardiovascular and Thoracic Surgery, Department of Surgery, Duke University Medical Center, Box 3340, Durham, NC 27710 (E-mail: andrew.lodge@ duke.edu).

J Thorac Cardiovasc Surg 2021;162:1371-2

$0022-5223 / \$ 36.00$

Copyright (C) 2021 by The American Association for Thoracic Surgery

http://dx.doi.org/10.1016/j.jtcvs.2021.02.012
}

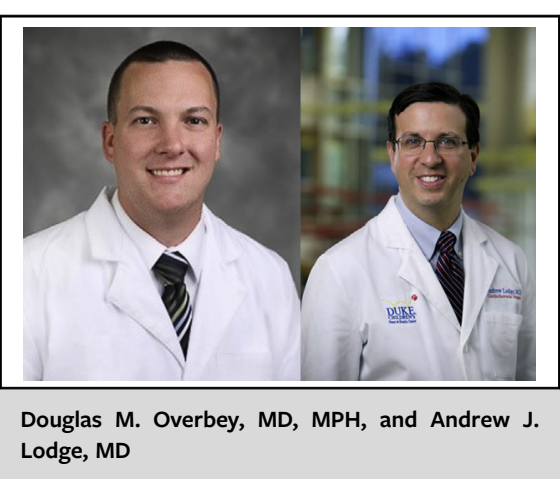

CENTRAL MESSAGE

Three decades of data at a single institution have shown favorable outcomes with neonatal heart transplantation. Frequency of neonatal transplant is decreasing as palliative surgical outcomes improve.

patients over 30 years highlighting the rarity of this operation overall. Furthermore, only 3 transplantations took place over the most recent decade, indicating an overall decline attributable to improved surgical palliative strategies such as the Norwood operation and its modifications. ${ }^{3}$ It is notable that a neonatal transplant has not been performed at this center since 2016 .

Survival at 5 years was $75 \%$ ( $95 \%$ confidence interval $[\mathrm{CI}], 46 \%-86 \%)$, at 10 years $72 \%(95 \% \mathrm{CI}, 45 \%-85 \%)$, and at 20 years $60 \%(95 \% \mathrm{CI}, 26 \%-70 \%)$. Transplants in patients listed as neonates, but transplanted after the neonatal period, showed similar survival rates. Rejection 